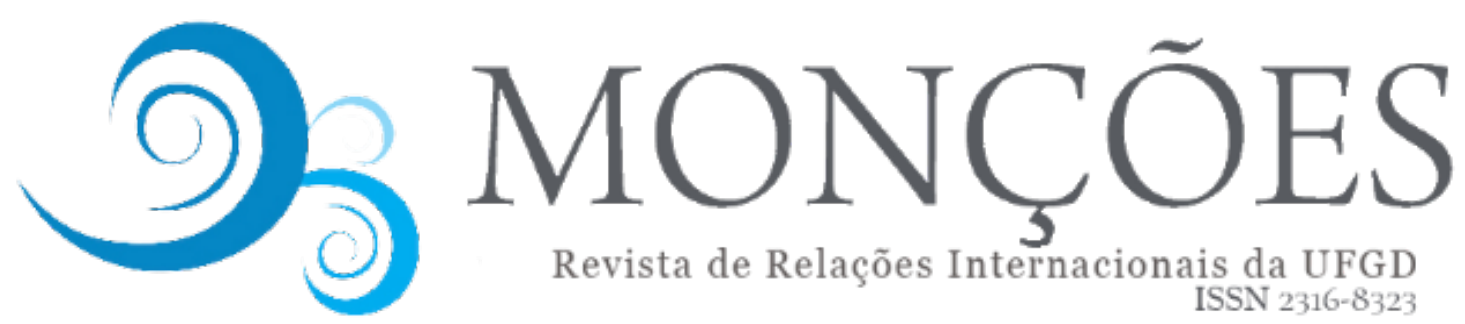

\title{
REPENSANDO A FRONTEIRA ENTRE ORIENTE E OCIDENTE: ENCONTROS CULTURAIS, NARRATIVA E TRANSGRESSÃO NOS ESCRITOS DE FATEMA MERNISSI
}

\author{
JESSICA DA SILVA C. DE OLIVEIRA \\ Doutora em Relações Internacionais pelo IRI/PUC RIO e Professora de Relações \\ Internacionais na PUC Minas Poços de Caldas
}

\begin{abstract}
RESUMO: Este artigo se centra nas narrativas e reflexões da escritora e ativista feminista Fatema Mernissi acerca dos encontros e fronteiras culturais e em sua tentativa de responder à questão: $O$ que está em jogo no pensar e escrever entre o Oriente e o Ocidente? E ainda, em como diferentes respostas a tal questionamento podem oferecer quadros para um engajamento decolonial de "dupla crítica" frente a saberes totalizantes, sejam eles ocidentais ou não-ocidentais, sem com isso implicar no apagamento do lugar de fala e experiência dos sujeitos resistentes - aqui, mais especificamente, mulheres muçulmanas. Lança-se luz sobre um aspecto específico do trabalho da autora, a saber, sua tentativa de, através do emprego de estratégias narrativas criativas que mesclam autobiografia e ficção, criar condições para desafiar representações dominantes sobre o Oriente e sobre a mulher muçulmana e promover um trabalho de "transcodificação" - ou seja, a busca por construir novos significados sobre os antigos com o objetivo de expor as dimensões violentas desses encontros, mas também de pensar as possibilidades de diálogo com a diferença.
\end{abstract}

PALAVRAS-CHAVE: encontros culturais, Fatema Mernissi, feminismo não-Ocidental.

\section{RETHINKING EAST-WEST BORDERS: CULTURAL ENCOUNTERS, NARRATIVE AND TRESPASSING IN FATEMA MENISSI'S WRITINGS}

\begin{abstract}
The article focuses on the reflections of feminist writer and activist Fatema Mernissi. It addresses Mernissi's critical engagements with the theme of cultural encounters and boundaries and her attempts to answer the question: What is at stake in thinking and writing between East and West? And also, on how different responses to such questions might offer different frameworks for a decolonial approach aiming at a "double critique" in the face of totalizing knowledge - whether Western or non-Western - without the setback of effacing one's locus of enunciation and experience of resistance of marginal subjects - here, Muslim women more specifically. In this way, I intend to explore a specific aspect of Mernissi's work, namely, her use of creative narrative strategies mixing autobiography and fiction in attempting to set conditions for challenging dominant representations of the Orient and to promote "transcoding" - i.e. the construction of new meanings over ancient established ones aiming to expose the violent dimensions of cultural encounters, but also rethinking the possibilities of engaging and dialogue with difference.
\end{abstract}

KEYWORDS: cultural encounters; Fatema Mernissi; non-Western feminism. 


\section{Introdução}

I am frightened when crossing borders because I am afraid of failing to understand strangers.

Fatema Mernissi, Scheherazade Goes West

Em The Practice of Everyday Life, Michel de Certeau escreveu: "[o] que o mapa corta, a história atravessa" (CERTEAU, 1984, p.130). A frase de Certeau ressoa com uma série de esforços dentro (e através) do campo das RI que compartilham o desconforto com o mundo estreito, autorreferencial e, não poucas vezes, inerte da disciplina. Dessa perspectiva, a lógica estatista de fronteiras rígidas e a concepção do mundo como "constituído de sujeitos delimitados dentro de comunidades políticas delimitadas" (MHURCHÚ; SHINDO, 2016, p. 2) não refletem a complexidade das vozes, experiências e visões de mundo encontradas quando damos maior importância a histórias em detrimento de mapas-múndi.

O presente artigo tem como objetivo geral explorar alguns dos significados e importância desse movimento de "trazer o mundo de volta às Rl" (SAJED, 2013, p. 2), seja no sentido de repensar categorias normalmente tidas como dadas nos estudos de política internacional - aqui, mais especificamente, as categorias "Ocidente" e "Oriente" (ou "não-Ocidente")1 -, seja no sentido de chamar atenção para as experiências de sujeitos historicamente marginalizados - mais especificamente, mulheres muçulmanas. Para tanto, propõe-se um engajamento com as reflexões da socióloga, escritora e ativista feminista marroquina, Fatema Mernissi $^{2}$ [1940-2015], sobre encontros culturais, fronteiras e possibilidades para

\footnotetext{
${ }^{1}$ No escopo deste artigo, o uso dos termos "não-Ocidente"/"não-Ocidental" alternativamente ou em conjunto com "Oriental" tem como objetivo salientar subjetividades, formas de pensamento, e espaços que podem ou não estar implicados na dicotomia Ocidente/Oriente - donde ambos termos adquirem um sentido geohistórico claro, como é o caso do "pensar/estar/escrever nas fronteiras entre Oriente e Ocidente" de que trata Mernissi -, mas que estão colocados às margens do lócus de privilégios materiais, epistemológico e ontológico que o referente "Ocidente" denota.

${ }^{2}$ Ao longo de sua carreira e compromisso com a agência histórica das mulheres no contexto da sociedade marroquina especificamente, mas também no chamado mundo islâmico em geral, a autora investigou a dinâmica sexual em sua sociedade, chamando atenção para a desigualdade experimentada por mulheres marginalizadas em trabalhos como Beyond the Veil (1975), Doing Daily Battle (1983) - o último consistindo em uma coleção de entrevistas de mulheres marroquinas publicadas em francês e traduzidas em 6 línguas - e The Forgotten Queens of Islam (1990). Na década de 1980 e auge do embate entre vertentes islâmicas radicais e ativistas da causa feminista no Magrebe, Mernissi ajuda a formar uma rede congregando acadêmicas e ativistas de toda região com agendas que convergiam na busca por pressionar por direitos políticos igualitários entre homens e mulheres em suas respectivas sociedades. Ver: MOGHADAN, 2017.
} 
superação de perspectivas orientalistas quando se tem em conta questões especificamente relacionadas à agência de mulheres muçulmanas e/ou árabes correntemente representadas como passivas e submissas no contexto de sociedades (e de uma religião) vistas como essencialmente patriarcais e opressoras. Se, de um lado, a dimensão dos encontros culturais, do pensamento de fronteira e do pensamento não-ocidental acerca dos modos de ser e agir na política internacional e global vem ganhando crescente atenção nos debates teóricos em $\mathrm{RI}^{3}$; de outro lado, ainda são escassos os engajamentos com o trabalho de autoras feministas não-ocidentais que tenham se dedicado a pensar a dimensão de gênero a partir de suas experiências, de suas histórias locais, ao mesmo tempo em que deslocam o Ocidente de uma posição de privilégio ao lançarem foco à produtividade e aos limites operando na zona de contato entre culturas.

Através de narrativas que misturam memórias pessoais e reflexões sobre os antagonismos interculturais duradouros entre 0 chamado Oriente/nãoOcidente/Leste e o Ocidente, Mernissi aborda a questão da alteridade enfatizando a complexidade cultural em detrimento de leituras homogeneizadoras e reificadoras acerca dos encontros entre Oriente e Ocidente. No espaço deste artigo, lança-se foco sobre duas de suas principais obras - Dreams of Trespass (1994) e Sheherazade Goes West (2001), publicadas originalmente em francês e inglês (respectivamente) -, nas quais a autora adota uma escrita situada entre autobiografia e ficção, e dialoga diretamente com uma audiência ocidental. Em ambas Mernissi avança uma análise transcultural da produção e da recepção de representações de mulheres do Oriente Médio em obras de arte, literatura, filosofia e outros textos ocidentais. Dentre outras coisas, a autora busca desestabilizar representações monolíticas das mulheres (e sociedades) muçulmanas, bem como concepções rígidas sobre fronteiras e encontros entre culturas, visualizando Oriente e Ocidente como paisagens experienciadas, em vez de referenciais geográficos, culturais ou históricos fixos.

Pretende-se explorar aqui um aspecto específico do trabalho da autora, a saber, sua tentativa de estabelecer as condições para desafiar representações dominantes sobre o Oriente e promover um trabalho de "transcodificação"

\footnotetext{
${ }^{3}$ Ver, por exemplo: INAYATULLAH, BLANEY, 2004; SAJED, 2013; SHILLIAM, 2012.
} 
(BERNARDI, 2010) - ou seja, a busca por construir novos significados sobre os antigos com o objetivo de promover o diálogo intercultural entre os sujeitos e locais do Oriente/não-Ocidente e do Ocidente, sem necessariamente antagonizar tais referentes. Junto à autora, questiona-se: O que está em jogo no pensar e escrever entre o Oriente e o Ocidente - sendo mulher, árabe e muçulmana? E ainda, de forma mais ampla, como diferentes respostas a tal questionamento podem oferecer quadros para um engajamento decolonial de "dupla crítica" (KHATIBI, 1983/1970), ou seja, a rejeição de saberes totalizantes, sejam eles ocidentais ou não-ocidentais, sem com isso implicar no apagamento do lugar de fala e experiência dos sujeitos resistentes? Nesse âmbito, busca-se ainda intercruzar e contrastar as reflexões de Mernissi com as do também sociólogo e romancista marroquino Abdelkebir Khatibi, especialmente no que tange aos encontros culturais entre Oriente e Ocidente e às possibilidades e limites da dupla crítica.

Personificando os dilemas de alguém que está ciente da complexidade da hudud (a "fronteira sagrada" que distingue o permissível do proibido) tanto nas sociedades de maioria muçulmana quanto na dimensão mais ampla dos encontros entre Oriente e Ocidente, os escritos de Mernissi emergem como tentativas de narrar o tipo de "desorientação" que afeta as fronteiras epistemológicas, culturais e pessoais ao se lidar com a questão da diferença para além de protocolos estabelecidos e representações monolíticas. Ao fazer uso criativo de estratégias narrativas, Mernissi busca mobilizar, através de suas personagens, diferentes significados e visões de hudud, com o intuito de desestabilizar qualquer tentativa de conferir um único sentido ao termo e, com isso, sinalizar para o fato de que fronteiras (entre indivíduos e culturas) podem ser mais fluidas, incertas e negociáveis do que o esperado. No escopo deste artigo, a reflexão em torno da noção de hudud vem para, dentre outras coisas, lançar uma sombra de dúvida sobre um binário que é tão amplamente aceito: Ocidente/Oriente (ou, ainda, e de forma ainda mais ampla, não-Ocidente), bem como explorar alguns dos mecanismos que permitem que tais binários sejam reproduzidos. No escopo do dossiê Teoria das Relações Internacionais no Brasil, busca-se lançar luz não somente sobre o legado do pensamento de Fatema Mernissi enquanto importante nome dentre as feministas não-ocidentais contemporâneas, mas também sobre possibilidades de diálogo com 
outras perspectivas do Sul Global ${ }^{4}$ também atentas à questão de gênero e sensíveis a idiossincrasias políticas, sociais e culturais e à importância do lugar de fala mesmo quando o foco recai sobre estruturas mais amplas de desigualdade operando em âmbito global. As reflexões de Mernissi convidam ao exercício de tratar o lugar de fala e a diferença não como um empecilho para o engajamento, mas combustível para criar conexões entre teoria e prática, e entre a diversidade de histórias locais de opressão e resistência e suas similitudes e diferenças quando transpostas em contextos mais amplos como os da política internacional e global.

\section{Encontros culturais, fronteiros e o discurso Orientalista}

Em Decolonizing Methodologies, Linda Tuhiwai Smith (1999) analisa como a narrativa do triunfo do Ocidente e do saber ocidental enquanto (supostamente) universal, objetivo e civilizado se baseia em uma ficção, a saber: o "mito eurocêntrico do Ocidente intocado e original" (HOBSON, 2004). Em tal cosmogonia social, povos "orientais", "nativos" e, portanto, "não-ocidentais", somente tiveram contato com o conhecimento, a civilização e o progresso através "do Ocidente, pelo Ocidente". "Através do imperialismo", nos lembra autora, "tais culturas, povos, e seus Estados-nação são reposicionados como 'Orientais', ou 'outsiders' de forma a legitimar a imposição do regime colonial" (SMITH, 1999, p. 63). Mais do que um marcador geográfico ou geohistórico, Ocidente aqui se refere, portanto, a uma posição de privilégio ontológico e epistemológico que também se converte em privilégios materiais no âmbito do sistema-mundo moderno/colonial (MIGNOLO, 2012).

A história dos encontros entre Oriente e Ocidente se apresenta, então, como um caminho de mão única, no qual fronteiras são (supostamente) rígidas e há uma clara separação entre "o Ocidente e o resto", o centro e suas margens, entre aqueles que são capazes de falar em nome de outros e representar esses outros, e

\footnotetext{
${ }^{4}$ Nesse sentido, Marlise Matos nos convida a refletir sobre a possibilidade de uma nova proposta teórica feminista - ou mesmo uma nova "onda" - na qual perspectivas do Sul passam ao centro do palco enquanto fontes para debater as lacunas deixadas por perspectivas excessivamente baseadas em um "olhar do Ocidente" hegemônico e para reimaginar as possibilidades em torno de um feminismo global (ver MATOS, 2010).
} 
aqueles que são, em contrapartida, o que Abdelkebir Khatibi chama de "sociedades silenciosas" (KHATIBI, 1983/1981, p. 50). Do ponto de vista orientalista, as "sociedades silenciosas" não têm nada de relevante a dizer. Mais especificamente, o orientalismo - exemplo emblemático do discurso do "Ocidente e o resto" (HALL, 1992) - fabrica uma imagem permanente de um "Ocidente" superior, racional e vanguardista, que é definido negativamente contra um "Outro" não menos imaginário, o "Oriente" inferior, irracional e atrasado (KHATIBI, 1983/1974, 1978). O Oriente deixa de existir em si mesmo ou em seus próprios termos (SAID, 1978, p.3).

A faceta Orientalista do discurso do "Ocidente e o resto" engendra pelo menos três principais imagens interrelacionadas que, juntas, nutrem visões comuns de Oriente e Ocidente. Em primeiro lugar, a imagem de que ambos Oriente e Ocidente são entidades geohistóricas bem demarcadas e hierarquicamente quando não antagonisticamente - dispostas; em segundo, o obscurecimento do caráter polifônico e multifacetado do "Oriente", favorecendo imagens que remetem a um território homofônico, monológico e imutável; em terceiro, o apagamento da zona de contato que surge mediante os encontros culturais. Como sugerido por Stuart Hall (depois de Edward Said) e Abdelkebir Khatibi (antes de ambos Said e Hall), tal é a força e persistência das ideias orientalistas que até os acadêmicos contemporâneos mais bem intencionados seguem contagiados por elas - incluindo aqueles que de alguma forma procuraram desconstruir o Ocidente em suas ganas universalistas.

A ausência da zona de contato forjada nos encontros entre Oriente e Ocidente aparece, portanto, como um silêncio revelador, justamente o tipo de silenciamento que intelectuais trabalhando a partir de perspectivas críticas e atentas à diferença colonial e à violência epistêmica (ver Mignolo 2009) contra saberes subalternos não-ocidentais buscam desmantelar. No entanto, como salienta Khatibi, o que acontece quando sociedades (e subjetividades) silenciadas pelo discurso orientalista encontram caminhos para finalmente serem ouvidas é a "desorientação". O autor destaca, por exemplo, como o tropo do "árabe dócil”, recorrente no discurso orientalista, é uma remanescência da figura do "árabe literário" a qual, por sua vez, aparece para ilustrar a suposta imutabilidade e autenticidade de uma essência que remonta ao período pré-islâmico e às ruínas perdidas do deserto beduíno (KHATIBI, 1983/1974). Ambos tropos persistem nos nossos dias de 
diferentes formas como uma maneira recorrente de representar povos de maioria muçulmana e/ou árabe a partir do Ocidente. Tal representação, contudo, nada diz sobre as sociedades magrebinas contemporâneas, a partir de onde Khatibi, assim como Mernissi falam - e as quais, sobretudo, não são exclusivamente de origem árabe -, ou sobre quem se reconhece sob o signo "árabe", mas cujo comportamento e demandas político-sociais não obedecem a tais exercícios de categorização (ver TOUMI, 2002). Segundo Khatibi, trata-se, portanto, da ansiedade orientalista de representar o Outro árabe através da "inebriação da diferença intratável" - ou seja, a diferença da diferença. A complexidade que a palavra "intratável" sugere aqui traduz principalmente o desejo orientalista de limitar a diferença ao exotismo, capturando o Outro através da imagem de uma alteridade total, porém paradoxalmente intangível. Neste discurso, o "direito à diferença" do sujeito Oriental derivado de fantasias de autenticidade em relação a esse objeto observado (logo, observável) funciona como uma recusa (ou excusa) a encontros reais com a diferença. Como salienta Khatibi, não há aqui intenção de travar um diálogo com a diferença (KHATIBI, 1983/1974, p.134); somente a ânsia de capturá-la em representações estáticas investidas de um discurso de verdade.

Khatibi nos lembra, no entanto, que a literatura árabe bilíngue, como no caso da chamada literatura francófona magrebina ${ }^{5}$ - onde se incluem escritos do próprio autor e onde também é possível enquadrar os primeiros engajamentos de Mernissi e outras autoras e autores - que vai florescer com mais força no contexto após a descolonização ${ }^{6}$, é exemplo do tipo de cruzamento de fronteiras que acontece na zona de contato entre culturas. Neste caso, um encontro marcado pelo imperialismo e pela violência colonial da presença europeia, predominantemente francesa, nos séculos XIX e XX no Maghreb. Segundo Khatibi, a literatura francófona do Magrebe condensa não apenas a marca dessa violência colonial, mas também a variedade de elementos que desorientam o pesquisador/observador orientalista que não espera que seu objeto de observação seja capaz de se apropriar da sua própria língua e fazer uso dela para retornar o olhar (ver KHATIBI, 1983/1974, p.141).

\footnotetext{
${ }^{5}$ Para um panorama sobre o surgimento, história, e importantes nomes da literatura francófona vinda do Magrebe, ver: BENSMAÏA, 2003; WOODHULL, 1993; OLIVEIRA, 2019.

${ }^{6}$ Marrocos e Tunísia se tornam independentes em 1956, ao passo que a Argélia somente em 1962, após o fim de uma sangrenta guerra contra a então metrópole França.
} 
A definição de Khatibi de "diferença intratável" aparece mais abertamente em seu artigo Pensée-autre (1981), no qual aborda a questão da identidade nas sociedades magrebinas no período após a descolonização. Segundo ele, existem dois discursos hegemônicos os quais as sociedades magrebinas tendem a abraçar como destinos possíveis no contexto pós-colonial: de um lado, um discurso que se alimenta da idealização de um passado islâmico glorioso e das aspirações relacionadas à possibilidade de transmutar a autenticidade e a conformidade dessa "tradição" para o momento presente; e, de outro lado, a imagem de um Ocidente tecnologicamente avançado alimentando aspirações relacionadas à transformação e à "modernidade". Como resultado, o Magrebe permanece um espaço impensado, esmagado (ou dividido) entre essas duas "metafísicas" ou "modos de pensamento" dominantes (KHATIBI,1983/1981, p.35-39). A diferença intratável é, assim, o resultado desse modo de autoentendimento favorecido por duas narrativas totalizantes opostas, nas quais prevalece uma relação difícil com a nãoconformidade e a incerteza. Em termos simples, o que Khatibi sugere é que o indivíduo magrebino se vê incapaz de confrontar a desilusão causada pelo abismo inevitável da diferença entre a realidade vivida e a realidade ideal contida em um desses modos de pensamento. Esse confronto (e as dificuldades em lidar com ele) é o que chama de "diferença selvagem" [différence sauvage] ou "diferença intratável", porque tende a enfatizar as inseguranças existentes no incorporar e (con)viver com a diferença que se quer negar - ou seja, a pluralidade de modos de pensamento e existência que marcam essa região, que não é tão somente ou indiscutivelmente nem muçulmana ou árabe e nem ocidental. No contexto do Magrebe, tais inseguranças são frequentemente traduzidas como memórias persistentes de uma experiência colonial dolorosa ou o ressentimento de não ser "completamente árabe" (JEBARI, 2017).

$\mathrm{Na}$ abordagem independente de Khatibi sobre o Orientalismo, é possível perceber que o relato histórico apresentado visa localizar o surgimento do "pensamento fronteiriço" - para utilizar a terminologia de Walter Mignolo (2012) como um antídoto contra a violência do discurso orientalista em relação aos povos árabes em geral, e ao Magrebe especificamente. Na "história local" oferecida por Khatibi - que tem como palco a Península Ibérica e o conflito entre muçulmanos e cristãos no século XVI -, o Ocidente também é definido em oposição ao que o autor 
chama de "nosso patrimônio", o Islã7, embora ele seja rápido em oferecer maneiras de pensar para além dessa dicotomia, passo necessário para preparar o palco para o dito "outro pensamento" [pensée autre], capaz de romper com a "máquina de incompreensão mútua" que é a história dos encontros entre Oriente e Ocidente desde então (KHATIBI,1983/1981, p. 15). A única maneira de escapar deste círculo de violência é a "dupla crítica" contra os fundamentalismos tanto do Ocidente quanto do Islã. A dupla crítica, esclarece o autor, é condição de possibilidade para o surgimento de um "pensamento outro", um pensamento que se afasta e não é mais concebível dentro de uma concepção linear ou mesmo dialética de desenvolvimento histórico (KHATIBI, p. 37). A dupla crítica de Khatibi pode ser lida como uma modalidade de pensamento ou conhecimento fronteiriço, ou seja, um modo de pensar que é diretamente emanado da história local e da perspectiva do intelectual subalterno (MIGNOLO 2012).

A próxima seção lança luz sobre a abordagem em muitos aspectos similar de Mernissi em suas reflexões sobre encontros culturais, fronteiras e possibilidades de resistência do sujeito subalterno - nesse caso, mulheres muçulmanas. Contudo, como será discutido mais adiante, se, por um lado, suas abordagens ecoam na busca por "desorientar" o discurso orientalista e na adoção de estratégias para "retornar o olhar" na busca por desmantelar a suposta primazia do Ocidente nos encontros culturais (coloniais); por outro lado, o compromisso de Mernissi com a "reinvenção" da mulher muçulmana enquanto um significante plural extrapola o compromisso intelectual de subverter discursos dominantes - a saber, orientalista, islâmico, falocêntrico - e enfatiza a busca por efetuar mudança social através das estruturas políticas existentes. Para Mernissi, estruturas de imaginação e narrativa podem ser convertidas em ferramentas de resistência e mudança social - instâncias

\footnotetext{
${ }^{7}$ Enquanto Edward Said (1978), em sua célebre obra, vê o orientalismo como a imaginação cultural hegemônica do mundo moderno que tem suas raízes no imaginário predominante entre as potências coloniais europeias do século XIX, Khatibi argumenta que a oposição na qual o orientalismo se sustenta remonta de fato ao início da história do sistema mundial moderno e ao conflito entre cristãos e mouros na Península Ibérica do século XVI. Isso, juntamente a ideologia dominante à época, ou seja, o Renascimento, é o que Khatibi chama de "ocidentalismo" - ou o momento em que a imagem de um Ocidente autossuficiente, virtuoso e superior surge na Europa (KHATIBI, 1983/1981). Mesmo após a decadência das primeiras potências coloniais européias, Portugal e Espanha, a configuração epistemológica greco-romana e cristã, isto é, o ocidentalismo, permaneceu como o modo dominante de pensamento, ao passo que o conhecimento islâmico "se tornou um critério para julgar e subalternizar" outras formas de pensamento que não podem ser justificadas dentro do conhecimento ocidental (MIGNOLO, p. 61).
} 
onde a dupla crítica de que fala Khatibi apresenta potencialidades, mas também limites.

\section{Imaginação e narrativa como estratégia de resistência nos escritos de Fatema Mernissi}

"Eu nasci em 1940, em um harém em Fez" é a frase que abre Dreams of Trespass (1994), livro onde Fatema Mernissi conta a experiência de crescer no Marrocos ainda sob domínio colonial da França, intercruzando memórias pessoais com uma narrativa que também privilegia pontos de vista que atribui a algumas mulheres importantes em sua vida. Dentre outros efeitos, percebe-se a busca por desestabilizar concepções ocidentocêntricas de Islã, da mulher muçulmana e de instituições como o harém - que, durante muito tempo, marcou a geografia e a política da vida em família no mundo muçulmano. Já em Scheherazade Goes West (2001), Mernissi apresenta uma análise da produção, da recepção e da reprodução de imagens da mulher do Oriente Médio através de obras de arte e de filosofia ocidentais, em uma narrativa em que sua experiência pessoal e suas reflexões enquanto intelectual mulher, feminista e muçulmana se intersectam com seus esforços de examinar os antagonismos entre Oriente e Ocidente.

$\mathrm{Na}$ abordagem avançada pela autora, o poder da imaginação aparece como uma importante dimensão do persistente antagonismo entre o Oriente e o Ocidente. Em Scheherazade, por exemplo, Mernissi se pergunta por que a imagem dominante do harém no imaginário ocidental (como nas pinturas de artistas como Picasso, Ingres, Delacroix e Matisse, mas também na indústria cinematográfica de Hollywood) não apresenta a tensão e a subversão constantes no dia-a-dia do harém em que ela cresceu no Marrocos (MERNISSI, 2001, p.14, 16). “O meu harém estava associado a uma realidade histórica [enquanto] o deles estava associado a imagens artísticas... [que] reduziam mulheres a odaliscas (um termo em turco para designar mulheres escravas)"8 (MERNISSI, p.14). É importante ressaltar que ela aponta para

\footnotetext{
8 My harem was associated with a historical reality [while] [t]heirs was associated with artistic images... [which] reduced women to odalisques (a Turkish word for a female slave)".
} 
o paradoxo de que o harém fictício que habita o imaginário ocidental e alimenta fantasias do exótico em relação ao Oriente experimentou circulação e credibilidade mais amplas do que o harém factual, a saber, um sistema de organização doméstico agora extinto na maioria dos países muçulmanos. Ao se contrastar as representações artísticas do harém em diversas partes da Europa com as que predominam no mundo islâmico, segundo Mernissi, não é incomum a impressão de que se tem diante de si dois mundos completamente diferentes.

Como problematiza a autora, Ingres, Picasso e outros famosos que se dedicaram a retratar o harém somente enxergaram a mulher muçulmana como uma figura passiva - ainda que misteriosa e exótica - e pronta para docilmente servir de objeto para o olhar fetichizante ocidental. Dito de outra forma, as representações problemáticas do harém no Ocidente também escondem uma deturpação da imagem das mulheres muçulmanas como belezas isoladas, passivas e controláveis no tempo cativo da estética e do olhar orientalista. Em outra passagem de Scheherazade, Mernissi traz uma análise mais profunda do ideal muçulmano de beleza feminina, mostrando como as mulheres retratadas em miniaturas persas por artistas muçulmanos (principalmente as da princesa Shirin, protagonista do conto "Krusraw e Shirin", escrito pelo poeta Nizami no século XIII) vêm para transgredir o modelo dominante de reclusão feminina estabelecido em certos países de maioria muçulmana (MERNISSI, 2001, p. 170). Shirin - no conto, ela mesma uma fugitiva de um harém - é frequentemente retratada cavalgando sozinha pela floresta, à procura de seu parceiro, Krusraw; ou, quando ambos os protagonistas são retratados juntos, os dois frequentemente aparecem em cenas que salientam a agência de ambas personagens - Mernissi dá o exemplo de uma pintura em que aparecem juntos, caçando animais selvagens. Shirin simboliza, portanto, o papel ativo das mulheres, e não uma sexualidade passiva e nua. Como sustenta a escritora, tais características encapsulam a essência da feminilidade no imaginário muçulmano, no qual as mulheres são "o Outro poderoso dotado de vontade pessoal" (MERNISSI, p.137). Mernissi argumenta ainda que essa seria a razão principal para a existência do harém e de outras formas de isolamento e barreiras à participação de mulheres na vida pública no passado e no presente de suas respectivas sociedades.

Como destaca Mernissi, no mesmo contexto em que franceses e britânicos produziam seus retratos de odaliscas em poses letárgicas e lascivas na Europa 
ocidental, acontecia não só a empresa colonialista europeia na África e na Ásia, mas também a não muito distante Turquia de Kemal Atatürk, onde se promulgavam leis civis que empoderavam mulheres (MERNISSI, 2001, p.109). Dessa forma, se a odalisca é um tropo consolidado no imaginário de homens e mulheres no Ocidente sobre as mulheres no Oriente a despeito de seu papel enquanto agentes políticos, tal tropo certamente dialoga com a estrutura mais ampla de produção de conhecimento global e, portanto, aparece duplamente como causa e efeito da violência epistêmica - parafraseando Mignolo (2009) - sobre espaços, indivíduos e modos de pensamento não-Ocidentais. Tem-se aqui, portanto, uma primeira dimensão do poder da imaginação do qual fala a autora: a reificação de sociedades inteiras através da (re)produção de representações que remetem ao exótico e ao estático, podendo resvalar em - e justificar - argumentos e práticas imperialistas sobre povos "bárbaros" e "atrasados".

No retrato do harém que Mernissi pinta através de sua narrativa em Dreams, em contraste, o(a) leitor(a) se depara com um espaço político onde múltiplas histórias são encenadas, onde tragédia e transgressão aparecem em constante sobreposição e as relações entre homens e mulheres não se reduzem à mera repressão. Mulheres importantes na vida da autora - cuja voz se confunde com a da narradora e protagonista em uma narrativa que certamente mescla objetivos acadêmicos e literários - aparecem como personagens centrais, e são aquelas cujas visões de mundo, emoções, aspirações e contradições dão movimento à trama. Como Sajed (2013) destaca, a narrativa de Mernissi se concentra mais em "quem são (mulheres no harém)" do que em "o que" essas mulheres são (prisioneiras no harém)". Trata-se de uma dimensão importante porque, ainda que neste retrato do harém algumas generalizações também se façam presentes, dele também emerge a imagem de um espaço "onde mulheres empregam táticas criativas para manifestar seu senso de identidade" e praticam atos diários de resistência e subversão da hierarquia instituída (SAJED, 2013, p. 101). Encontra-se aqui, portanto, uma segunda dimensão do poder da imaginação. O harém de Mernissi é um espaço feminino de reclusão que pode ser marcado pela resignação e tristeza daquelas que se sentem impotentes dentro de suas paredes e portões, mas lançar foco exclusivamente sobre tal dimensão é contar apenas parte da história. Dreams "reconta o desenvolvimento da consciência feminista [de Mernissi] à medida que ela 
aprende com uma variedade de exemplos e questionamentos pessoais" (DONADEY, 2000, p. 86 apud BOURGET, 2013, p. 31). Nesse aspecto, o texto de Mernissi defende um "feminismo árabe-muçulmano cultivado em casa, emocionalmente afetado e trabalhado por mulheres de todas as classes sociais, tanto educadas quanto analfabetas" (BOURGET, 2013, p.31). Figuras amplamente conhecidas no mundo muçulmano são referências constantes, como a libanesa Zaynab Fawwaz, a egípcia Huda Sha'rawi e até mesmo Scheherazade (a heroína literária de As Mil e Uma Noites). Tais ícones dividem espaço com os pequenos atos heroicos das figuras femininas de sua própria família. As mulheres que Mernissi coloca sob holofotes são "agentes dolorosamente conscientes de suas limitações e restrições, mas com um profundo senso de seu papel político" (SAJED, 2006, p. 6).

O poder da narrativa, da oralidade e do contar histórias é uma dimensão importante da subversão feminina no harém de Mernissi. O Magrebe tem uma rica tradição oral (MERNISSI, 1994; 2001; ABU-LUGHOD, 1993) e, vale destacar, o ato de contar histórias é geralmente visto como uma prática exclusivamente feminina. Segundo a autora, a resistência toma forma precisamente nesta dimensão, já que é comum as mulheres fazerem uso da prática de contar histórias - comumente transmitidas em rodas de familiares e vizinhos - como meio de inverter posições de poder, desorganizando o imaginário e as lógicas que sustentam as estruturas e práticas patriarcais que são, em última instância, condição de possibilidade para existência do harém. "Em muitos desses contos, o sexo mais inteligente raramente é o que as autoridades religiosas costumam retratar como superior", salienta a autora (MERNISSI, 2001, p.9). Esse poder de contar histórias pode, assim, ser instrumentalizado tanto para resistir a códigos de pensamento e práticas hegemônicas e patriarcais (ou seja, uma estratégia criativa para o autoemponderamento), quanto ferramentas para impor, credenciar e reproduzir esses mesmos códigos.

Scheherazade, a emblemática contadora de histórias de As Mil e Uma Noites, é referência constante nos escritos de Mernissi. Segundo a autora, enquanto leituras feitas a partir do Ocidente tendem a ignorar a mensagem política de Scheherazade, interpretações desse mesmo conto no mundo muçulmano tendem a focar precisamente esse aspecto, destacando a "sensualidade inteligente" de Scheherazade (MERNISSI, 2001, p. 68). Em uma nota de rodapé, Mernissi narra 
sua surpresa quando percebeu que, no Ocidente, sua heroína literária favorita é trivializada como "uma artista adorável, mas ingênua, alguém que narra contos inócuos e se veste fabulosamente" (MERNISSI, p.15, n.2). Em Dreams, Mernissi reproduz a maneira como sua mãe costumava narrar a trajetória de Scheherazade e o significado político de suas habilidades como uma hábil contadora de histórias, cujo talento foi fator decisivo para que sua própria vida e de outras jovens fossem poupadas noite após noite (MERNISSI, 1994, p.13-16). Nas palavras de Mernissi, "Scheherazade é uma estrategista e poderosa pensadora" que fez uso da inteligência emocional e do poder da imaginação e da oralidade para desafiar o ciclo de assassinatos criado pelo rei Schahriar, enfatizando, assim, a "autodeterminação feminina" e a possibilidade de ultrapassar fronteiras (tanto materiais quanto imaginadas) e assim "transformar o mundo e aqueles que o habitam" (MERNISSI, p.13-16).

Em Scheherazade Goes West, a autora oferece ainda uma releitura do papel de Scheherazade e do ato de contar histórias como uma espécie de "mito civilizador moderno" (MERNISSI, 2001, p.51). Seus esforços podem ser vistos como "um símbolo do triunfo da razão sobre a violência" - onde "razão" significa, acima de tudo, a capacidade de estabelecer diálogo com a diferença, reconhecendo e respeitando as fronteiras dessa diferença e a imprevisibilidade desses encontros. Nesse ponto, é possível perceber que a mobilização de expressões como "mito civilizador" e "triunfo da razão" não é inocente, tendo em vista que Mernissi substitui o sentido normalmente empregado no discurso ocidental por outros menos violentos, ressignificando-as. A oposição contadora de histórias/Rei nos contos também remete ao conflito entre a Shari'a (a verdade sagrada) e a ficção no mundo muçulmano. Nesse sentido, o papel de Scheherazade está em paralelo com os quççaç ("contadores de histórias"), já que ambos lançam mão do contar histórias como estratégia para incitar reflexões sobre realidades de opressão e injustiça, não raramente encorajando mudanças de percepção e a transformação dessas realidades. Fazendo referência ao historiador Abdesslam Cheddadi, Mernissi conta, por exemplo, como os contadores de histórias da Idade Média eram considerados "instigadores da rebelião" e perseguidos no mundo muçulmano por questionarem a legitimidade dos guardiões da çidq ("verdade"). Tal prática, desprezada pelas elites e poderosos, adquire relevância política precisamente porque, ao abrir canais para 
imaginar mundos alternativos e recuperar espaços para agência através do questionamento, acaba por transgredir a fronteira entre fato e ficção, tornando wahm ("imaginação") um meio de interferir concretamente na realidade (MERNISSI,2001, p.53-54).

A admiração e o apelo de Mernissi ao poder do conhecimento e ao domínio das palavras não estão necessariamente relacionados às suas credenciais acadêmicas - embora, como ela admite, o acesso à educação certamente a tenha ajudado a ascender a uma posição privilegiada. Diferente disso, ela encoraja seus leitores a refletir sobre a política dos menos privilegiados, ou seja, sobre como sujeitos marginais aprendem a utilizar as armas que têm em mãos para resistir à violência das estruturas que os oprimem. As mulheres iletradas e isoladas de sua infância não são, portanto, sujeitos indefesos e sem voz; tiveram apenas que aprender maneiras alternativas de expressar sua individualidade e de se fazer ouvir - tal qual Scheherazade. A resistência, como Mernissi parece ressaltar, também vem de lugares inesperados. Como afirma Lila Abu-Lughod em seu estudo sobre as práticas de contar histórias no contexto das tribos beduínas Awlad 'Ali do Egito, uma "história está sempre situada", já que presume um(a) narrador(a) e uma audiência; consequentemente, apesar de sua íntima conexão com tempos antigos, memórias e práticas traduzidas como "tradição", histórias são contextuais e "[sua] narração essencialmente motivada" (ABU-LUGHOD, 1993, p.12). No contexto do harém onde Mernissi cresceu, a oralidade serve não apenas ao propósito de transmitir mitos atemporais ou recontar eventos passados e lições morais a eles associados - que, aliás, também estão subordinados ao aspecto situacional de narrativa e à experiência de vida daquela que narra -, mas também às tentativas das mulheres de fazerem frente a práticas que normalmente as condenariam ao silêncio.

Nesse sentido, o que ambas Mernissi e Abu-Lughod demonstram é que a oralidade, a prática de contar histórias, usualmente concebida como uma forma "tradicional" de conhecimento, está muito viva apesar de seu status de "saber subjugado" - para utilizar o termo de Walter Mignolo - nos círculos intelectuais ocidentais (MIGNOLO, 2012, p.64. ver MIGNOLO, 2009). Apesar de marginalizado pelo conhecimento (ocidental) moderno e pela supremacia do signo escrito que é por este endossado, o saber fundamentado na oralidade sempre coexistiu com definições institucionais de filosofia e conhecimento (MIGNOLO, 2012, p.64; ver 
MIGNOLO, 2009). Tendo em conta o nexo poder-conhecimento, o tratamento da oralidade como uma espécie de "primitivismo" (ONG, 2002, p. 170-171) ou, como a própria Mernissi nos lembra, um "símbolo das massas ignorantes", mero folclore ou, não raramente, como fonte de rebelião, não é meramente acidental, mas obedece à lógica da fronteira entre o que é conhecimento válido sobre a realidade e o que é mera ficção (MERNISSI, 2001, p. 55). Sem o intuito de adentrar em um debate epistemológico mais profundo sobre o que é conhecimento ou como nos é possível conhecer a realidade, é possível extrapolar e sugerir que o que ambas Mernissi e Abu-Lughod ${ }^{9}$ conseguem mostrar é que "a conexão entre experiência, significado e conhecimento tal como foi imaginada no âmbito da ciência moderna (positivista) não pode mais ser sustentada" (WIBBEN, 2011, p. 44; ver MERNISSI 1988; SMITH 1999; WOODHULL, 1993).

Mernissi traz à tona, então, o aspecto político da narrativa de duas maneiras importantes. Primeiro, ela destaca o papel da narradora/contadora de histórias ao salientar as mulheres do harém como portadoras da palavra e agentes cujas habilidades narrativas se tornam uma arma importante. Em segundo lugar, sugere que a audiência também tem papel crucial em conferir autoridade e relevância às narrativas e àquele(a) que narra. Ou seja, quando um ouvinte ou um grupo de ouvintes (por exemplo, sujeitos marginalizados, como as mulheres no harém) decidem parar de ouvir (por exemplo, narradores em posições privilegiadas de poder, como o homem chefe de família no harém), a relação de dominação é subvertida. Nesse sentido, a possibilidade de resistência reside tanto no falar como no ouvir. Ao "ponderar sobre as relações de poder e sobre as hierarquias presentes no harém, [Mernissi] visualiza a resistência como um 'embaralhamento das cartas', uma 'confusão de papéis'" (SAJED, 2006, p. 6; ver MERNISSI, 1994, p.152).

\footnotetext{
${ }^{9}$ Cabe destacar que argumentações de Mernissi e Abu-Lughod partem de pontos de vistas diferentes no que tange à relação entre práticas de oralidade e o nexo saber-poder. De um lado, Abu-Lughod por vezes se apressa em enaltecer a prática de contar histórias enquanto antídoto para a violência inerente às práticas de generalização pelas ciências sociais as quais, na sua visão, endossam a supremacia do discurso da "diferença cultural" e da busca por tornar o "outro" não-Ocidental em objeto de conhecimento. De outro lado, Mernissi parece menos interessada em dar à oralidade e à prática de contar histórias o status de "método" para produção de etnografias mais polivocais. O foco da última está sobretudo em afirmar a subversividade das mensagens políticas que tais narrativas podem carregar. Sua narrativa revela situações em que a relação entre narradora e audiência é eficiente em deturpar hierarquias, emponderando aquelas (nesse caso, as mulheres no harém) cujas vozes passam a ocupar o centro do palco.
} 
Assim, o nexo poder-conhecimento aparece como dimensão importante na escrita de Mernissi, ainda que a autora o desloque para lugares por vezes inesperados. Incluem-se também nesse âmbito as formas como a produção e o consumo de conhecimento operam em ambientes institucionais tais como a academia e a mídia. A decisão de escrever Scheherazade em Inglês, por exemplo, não é inocente. Como explicitado pela própria autora, o objetivo era chamar atenção de uma audiência ocidental para a pluralidade de cosmovisões e vozes que compunham o chamado mundo islâmico; e, simultaneamente, questionar visões comuns sobre o Oriente, sobre os encontros entre Oriente e Ocidente e, especialmente, sobre o imaginário em torno da figura da mulher muçulmana. Mernissi performatiza através da escrita a dimensão da agência feminina concebida por ela como motor de resistência e transformação na sociedade a partir da qual fala. Assim como no conto de Scheherazade, o que parece estar em jogo para a autora é nada menos que a sobrevivência.

\section{Pensando entre o Oriente e o Ocidente: fronteiras, possibilidades de transgressão e os limites da dupla crítica}

No processo de lidar com os estereótipos ocidentais em relação à sua sociedade e a si mesma (enquanto mulher muçulmana) em Scheherazade, Mernissi aborda também a força da sua própria visão estereotipada ao retornar o olhar para seus interlocutores europeus. Nesse sentido, a autora/narradora/personagem se coloca na posição de um exemplar da complexidade cultural dos encontros entre Oriente e Ocidente: "Porque lá estava eu usando meu enorme bracelete prateado berber e meu batom vermelho Chanel, ninguém notou minha ansiedade (...)"10 (MERNISSI, 2001, p. 2). Jogar com a força dos estereótipos e o uso de uma linguagem emocionalmente carregada é, portanto, parte de sua estratégia para enfatizar essa complexidade, especialmente em relação à alteridade nas interações entre, de um lado, mercados globalizados e tecnologias difundidas de transporte e comunicação e, de outro lado, a tradição - entendida aqui como "a persistência da

\footnotetext{
${ }^{10}$ No one noticed my anxiety during my book promotion tour, however, because I was wearing my huge Berber silver bracelet and my red Chanel lipstick".
} 
memória", ou seja, uma dimensão viva da constante negociação entre práticas culturais e ideais de autenticidade (APPADURAI, 1996). Tendo isso em vista, nesta seção, propõe-se uma leitura da narrativa de Mernissi como uma tentativa da autora em direção a um movimento de "dupla crítica". Nas palavras de Khatibi (1983), a dupla crítica consiste em "colocar a episteme ocidental face à face com aquilo que ela impensadamente exclui e, assim, radicalizar suas margens, e não apenas em relação ao pensamento em árabe" - um dos muitos saberes e língua subalternizados trabalhando às margens do pensamento ocidental -, "mas em relação e em direção a um outro pensamento, ou seja, um pensamento que fala diferentes línguas, ouvindo cada palavra - e de onde ela veio" (KHATIBI, 1983/1981, p.63, tradução minha).

Para Khatibi, a decolonização, uma tarefa em si mais profunda do que a independência nacional em relação à metrópole, é um processo que necessariamente é perpassado pela dupla crítica. No contexto do Magrebe póscolonial, por exemplo, a dupla crítica abrangeria o exame crítico da herança dual em que os intelectuais magrebinos - dentre eles Mernissi e o próprio Khatibi - estão agora localizados, qual seja, a do "Ocidente" (entendido aqui como a "solidariedade estrutural" entre "imperialismo, etnocentrismo e o discurso da autossuficiência" na expansão das chamadas ciências sociais), e a das "tão teológicas, carismáticas e patriarcais" instituições da cultura árabe-islâmica (KHATIBI, 1983/1981, p.12). Nesse sentido, o que emerge da proposta de Mernissi de pensar e escrever entre o Oriente e o Ocidente é a tentativa de expor os padrões violentos presentes tanto no pensamento ocidental como no pensamento não-ocidental - ou seja, repensar tal dualismo em uma busca por alternativas "não-etnocidas" para pensar a diferença (KHATIBI,1983/1981, p.17). Como superar a hudud já internalizada em cada um de nós para pensar e lidar com a alteridade em um contexto global? - ambos Khatibi e Mernissi parecem questionar. Tal questionamento ressoa nas palavras de Mernissi quando relata, em inconfundível tom confessional, que:

Respeitar um ocidental é um ato heroico para um muçulmano, um lampejo de força, porque a cultura ocidental é tão agressivamente presente em nossa vida diária que temos a impressão de que já a conhecemos completamente. (...) Se pudéssemos ver os ocidentais como vulneráveis, nos sentiríamos mais próximos deles. Mas nós confundimos os ocidentais com o Super-homem, com arquitetos sem 
coração da NASA (...). Chocou-me descobrir que toda a minha herança Sufi não foi capaz de me proteger da forma mais óbvia de barbárie: a falta de respeito pelo diferente ${ }^{11}$ (MERNISSI, 2001, p. 25, tradução minha).

A consternação confessada pela autora traz à tona a dimensão dos encontros que se dão entre diferentes modos de produção, de pensamento e de existência e o contexto global contemporâneo, e a forma com que se afetam mutuamente. Neste âmbito, se, por um lado, tanto feridas coloniais como estruturas imperiais ainda operam significativamente, por outro, observa-se também a força para lutar pela "sobrevivência na transformação" e na busca incessante por um pensamento plural. Tem-se uma ponte aqui com a definição de "Terceiro Mundo" avançada por Khatibi, qual seja, uma diversidade de afirmações e visões políticas sobre o significado das transformações globais em curso e, ao mesmo tempo, um "nós" inequívoco quando se trata da consciência em torno da necessidade de transformação (KHATIBI, 1983/1981, p. 17). Nessa perspectiva, a decolonização aparece como "um processo no qual indivíduos tanto do 'Oriente' quanto do 'Ocidente' devem participar criticamente" (WOODHULL,1993, p.x). A decolonização, salienta Khatibi, pressupõe a dupla crítica; e esta, por sua vez, pressupõe a zona de contato entre culturas, uma vez que o objetivo é justamente capitalizar sobre as energias que dali emergem de maneira a gerar um pensamento crítico sobre a diferença.

Ambos Khatibi e Mernissi tentaram realizar ao longo de suas obras um movimento de "escrever/pensar entre o Oriente e o Ocidente" ao mesmo tempo em que adotavam o Magrebe - por si só um referencial geohistórico e cultural cuja ontologia "pluriversal", para tomar emprestada a terminologia de Walter Mignolo (2012), reside nos entremeios dos encontros entre Oriente e Ocidente - como "horizonte de pensamento" (KHATIBI,1977). Enquanto Mernissi lança seu olhar sobre estruturas de fantasia e emoção entre culturas, Khatibi se concentra nas estruturas de (re)produção do conhecimento, empreendendo uma espécie de sociologia do conhecimento a partir das fronteiras de duas tradições epistêmicas, a

\footnotetext{
11 "Respecting a Westerner is a heroic achievement for a Muslim, a tour de force, because Western culture is so aggressively present in our daily life that we have the impression we already know it thoroughly (...). If we could see Westerners as vulnerable, we would feel closer to them. But we confuse Westerners with Superman, with heartless, robotlike NASA architects (...). All my Sufi heritage, I was shocked to discover, did not protect me against the most obvious form of barbarism: the lack of respect for the foreigner."
} 
ocidental e a islâmica. Como Idriss Jebari (2017) destaca, esse movimento de adoção do Magrebe como um horizonte de pensamento (ou referencial epistemológico) reconfigurado por parte de um número de intelectuais norteafricano(a)s no contexto específico entre os anos 1970 e os fins da década de 1990 deve ser entendido como um chamado à ruptura radical com os modos de pensamento existentes, especialmente após a predominância de um pensamento nacionalista nas escritas acadêmica e literária pós-coloniais. No contexto após a descolonização, a nacionalização do pensamento a qual Jebari menciona se refere, dentre outras questões, ao processo de arabização então em curso na região, cujo um dos efeitos foi a marginalização tanto de línguas ditas autóctones do Magrebe (o Tamazigh e o Faraber, por exemplo) como da língua do ex-colonizador europeu. No último caso, aquele(a)s intelectuais e escritore(a)s cuja língua educacional e de carreira fora o francês se vêem em uma posição marginal não apenas no contexto global da produção de conhecimento (enquanto sujeitos não-Ocidentais), mas também dentro de suas próprias sociedades. Tanto Mernissi quanto Khatibi podem ser localizados dentro dessa dinâmica e seus esforços intelectuais são, em larga medida, um reflexo de tal condição. "Pensar o Magrebe", suas fronteiras culturais, linguísticas, religiosas e filosóficas foi, portanto, um passo importante para vincular marcos epistemológicos e culturais aos desdobramentos políticos naquele contexto (ver KHATIBI, 1977; OLIVEIRA, 2019).

Entretanto, o exercício de dupla crítica de Khatibi apresenta uma ambivalência, um limite, quando a dimensão de gênero é colocada em evidência. Um exemplo de tal ambivalência pode ser encontrado em seu prefácio para a edição marroquina (publicada em francês) de Doing Daily Battle: Interviews with Moroccan Women, de Mernissi. Ali, Khatibi toca na questão da diferença como limite; dessa vez, no entanto, a "diferença intratável" é imaginada pelo autor como dissimetria sexual:

[...] dissemos que a dissimetria desigual fixa o princípio em termos de dois territórios: o sexual (do lado feminino), o econômico e o político (do lado masculino). Esta regulação patriarcal e falocêntrica é denunciada hoje. Muito bem. Mas a utopia de uma igualdade absoluta e paradisíaca é excluída para nós. É claro que devemos ter igualdade econômica, legal e política, mas como se pode pensar o sexual fora de toda dissimetria? [...] Isso me parece absurdo. Tal dissimetria é 
insolúvel em si mesma e deve ser regulada por um pensamento que pensa sobretudo aquilo que é impossível dividir/compartilhar ${ }^{12}$ (KHATIBI, 1983, p. 8-9 apud WOODHULL 1993, p.xx, tradução minha).

Talvez em meio à ânsia de dar nome à sua própria diferença enquanto intelectual e escritor francófono magrebino que se vê marginalizado por não representar nenhuma das narrativas totalizantes dominantes em sua sociedade, Khatibi acaba ignorando o fato de que as mulheres ainda são aquelas a quem o poder da palavra fora negado na esfera pública. E, como visto, esta é justamente uma das formas de violência contra mulheres que Mernissi constantemente denuncia. Por um lado, em L'Orientalisme Khatibi celebra a condição bilíngüe magrebina enquanto uma importante fonte para o pensamento decolonial por permitir, em primeiro lugar, que o sujeito pós-colonial "pense em línguas" e, em segundo, que sociedades outrora silenciosas respondam diretamente àquelas que Ihes impuseram o silêncio. Por outro lado, a confiança exacerbada no indecidível e na força transgressora das reflexões que emergem da condição de estar/pensar entre o Oriente e o Ocidente em Khatibi muitas vezes se traduz como "diferença intratável", ou seja, como perspectiva em que a diferença aparece como limite e, portanto, como algo que está além da dimensão da comunicação e do diálogo que pode emergir da zona de contato. "Eu gosto de todas as línguas, portanto, todas as raças. [...] Mas a cor é antes de tudo um nome" (KHATIBI, 1990, p. 9). Assim, se em em alguns momentos Khatibi exitosamente se apropria da desconstrução ${ }^{13}$ e de outras estratégias filosóficas para repensar a condição das sociedades e

\footnotetext{
12 "(...) we have said that inegalitarian dissymmetry fixes the principle in terms of two territories: the sexual (on the feminine side), the economic and the political (on the masculine side). This patriarchal and phallocentric regulation is denounced today. Fine. But the utopia of an absolute and paradisaical equality is excluded for us. Of course, we must have economic, legal, and political equality, but how can one think the sexual outside of all dissymmetry? (...) This seems to me absurd. I mean that dissymmetry is insoluble in itself, and must be regulated by a thought that thinks that which is impossible to divide/share"

${ }^{13}$ Em suma, a "desconstrução" associada ao pensador franco-argelino Jacques Derrida - à qual Khatibi declaradamente se afilia - aponta para uma teoria da leitura que visa minar a lógica da oposição ou binarismo nos textos. Nas palavras de Derrida, trata-se de "[u]ma contestação da referência lingüística, da autoridade da linguagem , do 'logocentrismo"', é "um pensamento da origem e limites da questão 'o que é isso?', uma questão que domina toda a história da filosofia. Toda vez que tentamos pensar na possibilidade do 'o que é isso? ...', de colocar um questionamento sobre esta questão, ou nos questionar sobre a necessidade de tal vocabulário em uma certa linguagem, em uma certa tradição, etc, o que se faz naquele momento é somente até certo ponto a questão 'o que é isso?' [...] Tudo gira em torno da questão 'o que é isso?', a [desconstrução] lida com tudo o que esta questão comandou na história do Ocidente e da filosofia ocidental" (DERRIDA; ROGER POL-DROIT, 1992).
} 
subjetividades marginalizadas do Magrebe e do Terceiro Mundo em geral; em outros, parece ceder à tentação de desprover o termo "diferença" de todo e qualquer conteúdo e especificidade - seja ela cultural, racial, mas principalmente de gênero e se colocar à favor de uma poética da indecidibilidade que mais se afasta do que se aproxima da materialidade da violência no âmbito dos encontros e da fronteira entre culturas.

Mernissi, por sua vez, constantemente evoca imagens relacionadas aos atos de viajar e atravessar fronteiras como dois tropos interrelacionados que ajudam a iluminar o potencial transgressivo em detrimento de uma visão estática da hudud - a "fronteira sagrada" entre os seres humanos e divino, o bem e o mal, muçulmanos e cristãos, Oriente e Ocidente, homens e mulheres, entre o permissível e o proibido. Através de releituras seja das representações de feminilidade, seja da história da expansão islâmica dos tempos antigos até hoje, Mernissi busca desafiar diretamente o Orientalismo através do qual o Outro não-ocidental e muçulmano é reificado através de significantes como "bárbaro", "fanático", "atrasado", "não-civilizado", etc. Em Scheherazade, Mernissi se atenta ainda para visões mais contemporâneas não menos orientalistas sobre indivíduos e sociedades de maioria muçulmanas endossadas por governos ocidentais e pela mídia global. Em uma passagem, Mernissi resume o que para ela significa falar de um "Magrebe plural":

Um dos versos mais citados do Alcorão e que eu particularmente amo diz: "E nós lhes fizemos em diferentes nações e tribos, para que possam conhecer uns aos outros" (Sura 49:12). (...) Para entender essa ênfase muçulmana em aprender com a diferença, é preciso lembrar que o Islã se originou no deserto (atual Arábia Saudita) e que a prosperidade de Meca como centro comercial nos primeiros anos do calendário muçulmano se deveu aos viajantes que cruzavam constantemente as estradas que conectavam a África à Ásia e à Europa. Ao contrário do estereótipo racista que a maioria dos ocidentais têm do Islã, reduzindo-o à jihad, ou guerra sagrada, esta religião se espalhou da Arábia para a Indonésia através de rotas comerciais, via viajantes conversando entre si e aprendendo com as culturas uns dos outros. (...) Em seu tempo, essa sociedade islâmica internacional era certamente a sociedade mais difundida e influente do mundo. Essa diversidade fascinante e enriquecedora é uma mensagem 
forte constante em muitas fantasias muçulmanas $(. . .)^{14}$ (MERNISSI, 2001: 175-176).

Esse movimento de revisitar e repensar a atitude histórica das sociedades islâmicas em relação à alteridade serve a pelo menos dois propósitos diferentes da autora. Primeiro, desmantelar macronarrativas orientalistas onde muçulmanos aparecem como fanáticos, terroristas e atrasados e, simultanemante, tornar tais indivíduos e sociedades visíveis através de referenciais menos violentos. E segundo, para destacar a zona de contato sempre viva entre culturas de forma a transformar dualismos radicais em representações fictícias e meramente temporárias do Oriente e do Ocidente como duas entidades culturais antagônicas. Ao mesmo tempo, a narrativa de Mernissi vem para ilustrar como tradição e herança culturais, em vez de fixas no tempo e em territórios bem demarcados, podem ser compreendidas como a soma de memórias e fantasias persistentes que viajam através do tempo, do espaço e das mentes.

Mernissi não deixa de lançar mão de estereótipos em suas descrições do Oriente e do Ocidente, ainda que o faça com a intenção declarada de transgredir a narrativa ocidental dominante sobre sociedades e indivíduos não-ocidentais - em seus escritos, mais especificamente, sobre as mulheres muçulmanas. Sem dúvida, o perigo inerente a esse tipo de movimento está na possibilidade de com isso replicar a visão da diferença cultural como um discurso de oposições - amigo/inimigo, semelhança/diferença, dentro/fora, civilizado/bárbaro - no qual os protocolos dos encontros já estão dados. A narrativa de Mernissi não está livre de tais armadilhas e ambivalência em relação à alteridade - como ela mesma reconhece. Entretanto, em vez de glorificar a condição do "entrelugar" enquanto uma síntese pacífica de dois ou mais mundos ou culturas, a autora mobiliza a escrita como um exercício de autorrepresentação no qual o seu "eu narrado" viaja entre mundos apenas para

${ }^{14}$ One of the most quoted verses of the Koran, and one that I particularly love, reads: "And we made you into different nations and tribes, so that you may know about each other" (Sura 49:12). (...) To understand this Muslim emphasis on learning from differences, one has to remember that Islam originated in the desert (present-day Saudi Arabia) and that Mecca's prosperity as a center of trade in the first years of the Muslim calendar was due to travelers constantly crossing through on roads linking Africa with Asia and Europe. Unlike the racist stereotype that most Westerners have of Islam, which they reduce to a jihad, or sacred war, this religion spread from Arabia to Indonesia through trade routes, via travelers talking to one another and learning from one another's cultures. (...) In its time, this international Islamicate society was certainly the most widely spread and influential society on the globe. That fascinating and enriching diversity is a strong message that comes through in many Muslim fantasies (...)" 
chegar à difícil conclusão de que transgredir fronteiras internas pode ser tão desafiador quanto transgredir fronteiras externas (i.e., territórios e culturas). "Aterrorizo-me quando cruzo fronteiras porque tenho medo de não conseguir compreender o diferente" (MERNISSI, 2001, p. 1).

Nesse ponto, cabe salientar algumas das críticas levantadas à abordagem de Mernissi e que descortinam algumas das limitações do pensar e escrever entre Ocidente e Oriente, na sua condição de intelectual árabe e muçulmana comprometida com uma agenda feminista e de luta pelos direitos das mulheres (ver MOGHADAN, 2017). Como salienta Bourget, Mernissi acaba por minar a importância de seu projeto feminista ao enfatizar a imagem de uma instituição já obsoleta que é o harém, enquanto ignora desdobramentos importantes no Marrocos e em outras partes do mundo muçulmano, como o retorno do véu enquanto símbolo de múltiplos significados dentro dos movimentos pelos direitos civis, políticos e econômicos das mulheres (BOURGET, p. 32). Ainda que a representação da vida no harém trazida pela autora não satisfaça expectativas orientalistas, a distinção entre o harém imperial e o harém doméstico trazida pela autora, não poucas vezes, apenas desloca a imagem da odalisca por outra não menos problemática: a de mulheres muçulmanas escondidas atrás de véus e muros, vítimas de restrições similares, como segregação de gênero, poligamia, etc. "[A]s formas de opressão permanecem, apenas com pequenas variações" (BOURGET, 2013, p. 36). Em Dreams, apesar de celebrar o poder da palavra através do contar histórias e da beleza (num sentido diferente daquilo que identifica como os padrões ocidentais de beleza) como estratégias tradicionais de resistência das mulheres muçulmanas, Mernissi coloca em relevo o forte desejo de sua mãe pela modernidade - refletido em suas vestimentas e educação bilingue, na qual o francês por vezes aparece como forma de libertação - em contraposição direta às forças restritivas da tradição e do harém. “Tradição e Modernidade. Haréns e Liberdade. Uso e não-uso do véu (...)" - os "termos familiares através dos quais o Oriente é há tempos apreendido (e desvalorizado) e o Ocidente se constrói como superior" (ABU-LUGHOD, 2001, p.108) ${ }^{15}$. Dessa forma, a autora acaba não escapando da reprodução de imagens

\footnotetext{
15 "Tradition and Modernity. Harems and Freedom. Veiling and Unveiling. These are the familiar terms by which the East has long been apprehended (and devalued) and the West has constructed itself as superior".
} 
monolíticas, seja do Ocidente, seja do Oriente, do Islã, ou mesmo das mulheres muçulmanas - justamente aquelas cujas imagens e subjetividades busca complexificar e colocar em contraposição ao discurso hegemônico Orientalista (ver ZAYZAFOON, 2005; WOODHULL, 1993).

A forma como as histórias viajam, Mernissi destaca, é fundamental para entender as estruturas de poder e fantasia que marcam as relações entre homens e mulheres e entre as culturas em geral. O silêncio em relação à intelectualidade e ao pensamento estratégico da personagem Scheherazade e à dimensão política de $A s$ Mil e Uma Noites no Ocidente diz muito sobre como ocidentais fantasiam sobre os povos não-ocidentais e seu modo de ser e pensar. É nesse sentido que Mernissi lança mão da estratégia de "retornar o olhar" onde ela (enquanto sujeito e mulher não-ocidental) "observa o Ocidente observando o Oriente" e, a partir desse movimento, busca compreender e refletir sobre sua própria posição nessa teia de relacionamentos (SAJED, 2006, p.6). Nesse âmbito, Mernissi constantemente faz paralelos entre Scheherazade e ela mesma enquanto escritora e estudiosa muçulmana do Terceiro Mundo, cujos textos têm acesso ao público ocidental. Se para Scheherazade "manter o ouvinte entretido se tratava de uma questão de sobrevivência", o mesmo pode ser afirmado, como Mernissi parece sugerir, em relação à intelectual não-ocidental quando esta decide viajar ao Ocidente. Nesse movimento, para além de alertar sobre o papel ambivalente da(o) intelectual nãoocidental - como muitos já o fizeram - Mernissi também ressalta outros aspectos cruciais do papel do(a) crítico(a) pós-colonial. Em uma dimensão, ela ecoa o lembrete de Gayati Chakravorty Spivak de que o(a) intelectual pós-colonial deve estar ciente da impossibilidade de não habitar as estruturas de violência e violação que se está tentando problematizar (SPIVAK,1990, p. 72). Assim, toda vez que intelectuais pós-coloniais decidem incorporar o compromisso ético de construir um espaço para as vozes daquela(e)s que obviamente falam, mas raramente são ouvidos, devem ter em mente o perigo iminente de acabar objetificando essas vozes e/ou acabar se apropriando delas e tornando-as um eco da sua própria voz (ver WOODHULL, 1993).

Conceber a diferença não como um limite em si, mas uma oportunidade para o autoquestionamento e a dúvida, ou ainda, para reconhecer o perigo iminente da falha na habilidade de transgredir fronteiras, faz a dupla crítica teorizada por Khatibi 
um exercício muito mais desafiador do que este pareceu antever - perigos dos quais Mernissi parece estar consciente. Como fica claro na narrativa de Mernissi, exercícios de dupla crítica dependem necessariamente do movimento de cruzar fronteiras (físicas, emocionais e/ou epistemológicas). No entanto, como Khatibi sublinha, a busca por maneiras alternativas (e não-etnocidas) de conceber a diferença também requer um esforço de repensar e, por vezes, desconstruir fronteiras. No caso de Mernissi, se por um lado ela conceitua fronteiras como limites fortemente incrustados - por vezes tidos como "sagrados" - em convenções sociais e códigos culturais e religiosos, assim como nas mentes e atitudes dos indivíduos; por outro lado, ela acaba por redefinir o significado de fronteiras culturais em seus constantes esforços de repensar a dinâmica dos encontros entre Oriente e Ocidente. A dupla crítica em Mernissi ocorre quando ela se recusa em conceber o entrelugares que emerge a partir dos encontros culturais como uma mera síntese ou intervalo vazio que reifica a separação entre culturas. Para Mernissi, encontros culturais geram também um espaço de transcodificação onde as estruturas de fantasia, emoções e poder operando entre culturas ficam expostas, tornando possíveis reflexões críticas acerca de hierarquias entre sociedades, sujeitos e saberes no âmbito desses encontros. É um pontapé inicial, pode-se afirmar, em direção ao que Khatibi chama de "outro pensamento" acerca da diferença (KHATIBI, 1983/1981).

Fatema Mernissi contribui para a construção de um enfoque mais complexo sobre o Oriente e o Ocidente e o que está em jogo quando se recorre a um ou a ambos referenciais para retratar o encontro entre culturas. Ao mesmo tempo, não abandona totalmente a generalização e os binarismos enquanto recursos importantes - mais do que simples armadilhas - para repensar e rearticular as fronteiras e limites entre culturas, especialmente no âmbito de construções hierárquicas tal como no discurso orientalista. Em seus exercícios críticos, Mernissi acaba revelando algumas das dificuldades de uma tarefa tão desafiadora, mas ainda essencial, que é a dupla crítica. Em contrapartida, de forma consciente e não aproblemática, acaba revelando alguns traços de sua própria hudud face à complexidade dos encontros culturais. Como parece nos fazer acreditar Mernissi, talvez justamente aí residam os limites e, paradoxalmente, a potencialidade, de uma dupla crítica. 


\section{Considerações Finais}

O tema dos encontros culturais e do pensamento não-ocidental acerca dos modos de ser e agir na política internacional e global vem ganhando crescente atenção nos debates teóricos em RI. Para além da busca por construir um "bestiário" de concepções acerca da história e da política global, tal movimento chama atenção também para a necessidade de investigar e compreender a política da zona de contato entre as culturas, seja em sua dimensão violenta seja em seus momentos recessivos - ou seja, momentos em que o encontro com a diferença se revela como combustível para autorreflexão e dúvida (INAYATULLAH, BLANEY, 2004). Desse ponto de vista, a diferença pode ser traduzida de diversas maneiras, incluindo formas que estão além da linguagem da alteridade, da intratabilidade e do conflito. Apesar da ambivalência que se desprende de suas narrativas, o que parece louvável nos esforços de Fatema Mernissi é o fato de ela não se intimidar frente aos limites impostos pela diferença entre culturas e modos de pensamento. Apesar de tais limites (e limitações em seus engajamentos), argumentou-se aqui que as reflexões da autora e sua estratégia de "retornar o olhar" àquele(s) que lhe(s) é(são) culturalmente diferente(s) e/ou que historicamente ocupa $(m)$ a posição de opressor/colonizador/silenciador - seja ele o "outro" estrangeiro e ocidental ou os próprios homens de sua sociedade, incluindo seus familiares - representam uma importante contribuição para se pensar a dimensão de gênero no âmbito dos encontros culturais. Isso porque, ao perfomatizar tal estratégia, Mernissi sinaliza para a possibilidade de autorreflexão crítica e negociação mesmo quando isso implica expor a dimensão emocional mais profunda por trás de suas incertezas, conclusões equivocadas e mudança de planos quando em encontro com a diferença.

$\mathrm{Na}$ posição de intelectual de certo alcance internacional - ainda que às margens dos principais centros de consumo e reprodução do conhecimento em sua forma institucionalizada -, Mernissi é obviamente parte de, e está implicada em, uma rede de hierarquias de poder na qual acadêmicos e romancistas certamente não são os sujeitos mais marginalizados. A autora parece se recusar, contudo, a abraçar uma reivindicação impensada de marginalidade e a se esquivar do desafio de 
dialogar com a diferença. Em vez disso, parece optar pelo desconforto e pela autoexposição, sem se intimidar quando a ambivalência e os perigos de tais escolhas vêm à tona. Nesse sentido, quando a incerteza frente à diferença se manifesta como humildade e abertura à reflexão em vez de insegurança e medo como ambos Khatibi e Mernissi parecem sugerir -, o diálogo entre culturas, modos de pensamento e diferentes histórias locais parece mais plausível. Com isso, Mernissi parece tentar nos dizer, talvez se possa fazer emergir um "outro pensamento" sobre a diferença, a fronteira e o lugar de direito dos saberes subalternizados ao longo da narrativa histórica na qual pensamento ocidental aparece como saber universal.

\section{Referências}

ABU-LUGHOD, Lila. Review "Orientalism" and Middle Eastern Studies. Feminist Studies, vol.27, n.1, 2001, p.101-103.

Press, 1993.

Writing women's worlds: Bedouin stories. Berkeley: University of California

APPADURAI, Arjun. Modernity At Large - Cultural Dimensions of Globalization. University of Minnesota Press, 1996.

BENSMAIIA, Rèda. Experimental Nations or the Invention of the Maghreb. Princeton: Princeton University Press, 2003.

BERNARDI, Floriana. Gazes, Targets, (En)visions - Reading Fatima Mernissi through Rey Chow. Social Semiotics, 20:4, 2010, p. 411-423.

BOURGET, Carine. Complicity with Orientalism in Third-World Women's Writing: Fatima Mernissi's Fictive Memoirs. Research in African Literatures, vol. 44, 3, 2013, p. 30-49.

DERRIDA, Jacques; DROIT, Roger-Pol. "Quest-ce que la Déconstruction?". In: Le Monde, 12 de outubro de 2004. Disponível em: <http://medias.lemonde.fr/medias/pdf_obj/sup_pdf_derrida_111004.pdf> Acessado em 22 de outubro de 2016.

HALL, Stuart. The West and the Rest: Discourse and Power. In: ; GIEBEN, Bram (eds.). Formations of Modernity. Cambridge: Open University, 1992, p. 275331. 
HOBSON, John. The Eastern Origins of Western Civilisation. Cambridge: Cambridge University Press, 2004.

INAYATULLAH, Naeem; BLANEY, David. International Relations and the Problem of Difference. New York/London: Routledge, 2004.

JEBARI, Idriss. Rethinking the Maghreb and the Post-Colonial Intellectual in Khatibi's Les Temps Modernes Issue in 1977. The Journal of North African Studies, 2017, p. $1-18$.

KHATIBI, Abdelkebir. Amour Bilingue. Montpellier: Fata Morgana,1990. 112.

. Double Critique. In: Maghreb Pluriel. Paris/Rabat: Denöel, 1983(1970), p.43-

Le Maghreb Comme Horizon de Pensée. Paris: Les Temps Modernes du Maghreb, 375, 1977, p. 7-20.

. L’Orientalisme Désorienté. In: Maghreb Pluriel. Paris/Rabat: Denöel, 1983(1974), p.113-146.

Pensée-autre. In: Maghreb Pluriel. Paris/Rabat: Denöel, 1983(1981), p.9-42.

MATOS, Marlise. Movimento e Teoria Feminista: É Possível Reconstruir a Teoria Feminista a Partir do Sul Global? Curitiba: Revista de Sociologia Política, v. 18, n.36, 2010, p.67-92.

MERNISSI, Fatema. Doing Daily Battle: Interviews with Moroccan Women. New Brunswick/New Jersey: Rutgers University Press, 1988.

. Dreams of Trespass - Tales of a Harem Girlhood. New York: AddisonWesley Publishing Co, 1994.

. Scheherazade Goes West - Different Cultures, Different Harems. New York: Washington Square Press, 2001.

MHURCHÚ, Aoileann Ní;SHINDO, Reiko. Introduction: being critical and imaginative in International Relations. In: (eds). Critical Imaginations in International Relations. New York: Routledge, $\overline{2016}$, p.1-10.

MIGNOLO, Walter. Epistemic Disobedience, Independent Thought and Decolonial Freedom. Theory, Culture \& Society, vol. 26 (7-8), 2009, p. 159-181.

. Local Histories/Global Designs - Coloniality, Subaltern Knowledges, and

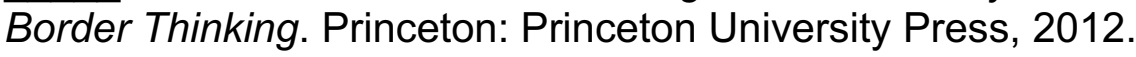

MOGHADAN, Valentine M. Feminist Movements in the Maghreb. In: Amrita Basu (ed.). Women's movements in the Global Era - the Power of Local Feminisms. New York: Westview Press, 2a ed., 2017, p. 333-360. 
OLIVEIRA, Jessica da Silva C. Postcolonial Maghreb and the Limits of IR. London: Palgrave Macmillan, 2019.

ONG, Walter J. Orality and Literacy - the technologizing of the Word. London/New York: Routledge, 2002.

SAID, Edward. Orientalism. New York: Vintage Books, 1978.

SAJED, Alina. Empire Writes Back: Between Dreams of Trespass and Fantasies of Resistance. Hamilton: McMaster University, Institute of Globalization \& the Human Condition, Globalization Working Paper Series 6/7, 2006.

. Postcolonial Encounters in International Relations: The Politics of Transgression in the Maghreb. New York: Routledge, 2013.

SHILLIAM, Robbie (ed.). International Relations and non-Western Thought Imperialism, Colonialism and Investigations of Global Modernity. New York/London: Routledge, 2012.

SMITH, Linda Tuhiwai. Decolonizing Methodologies: Research and Indigenous People. London \& New York: Zed Books, 1999.

SPIVAK, Gayati Chakravorty. The Postcolonial Critic. In: HARASYM, Sarah (ed.). The Postcolonial Critic - Interviews, Strategies, Dialogues. London/New York: Routledge, 1990, p. 67-74.

TOUMI, Alek B. Maghreb Divers: Langue Française, Langues Parlées, Littératures et Représentations des Maghrébins, à Partir d'Albert Memmi et de Kateb Yacine. New York: Peter Lang Inc., International Academic Publishers, 2002.

WIBBEN, Annick T.R. Feminist Security Studies: A Narrative Approach. New York: Routledge, 2011.

WOODHULL, Winifred. Transfigurations of the Maghreb: Feminism, Decolonization, and Literature. Minneapolis/London: The University of Minnesota Press, 1993.

ZAYZAFOON, Lamia Ben Youssef. The Production of the Muslim Woman: Negotiating Text, History, and Ideology. Oxford: Lexington Books, 2005. 